\title{
MEMÓRIA RASTRO EM POEMAS DE CONCEIÇÃO EVARISTO
}

\author{
Memory as trace in Conceição Evaristo's poems
}

\author{
Rosana Arruda de Souza \\ https://orcid.org/0000-0002-1378-070X \\ Universidade Federal do Mato Grosso, Programa de Pós-Graduação em Estudos de \\ Linguagem, Cuiabá, MT, Brasil. 78060-900 - secretariappgelufmt@gmail.com
}

\begin{abstract}
Resumo: A poesia de Conceição Evaristo é conhecida por desvelar aquilo que há muito permaneceu encoberto: a voz negra feminina, uma voz que, paradoxalmente, sempre existiu, mas era ecoada em ouvidos ensurdecidos. Agora, os tantos gritos perdidos da diferença podem ser ouvidos e os ouvidos são colocados à prova, pois reconhecer e vislumbrar a ausência trazida pelos signos - quando antes acreditávamos que eles traziam a presença - não é tarefa fácil. Assim, pois, entendemos e nos propomos a analisar os poemas da autora: sua poesia encerra o rastro - a ausência, o outro, que carrega em si uma potencialidade significativa justamente enquanto é sombra, pois as vozes negras estão em cena, mas, ainda, não estão à luz, entretanto estar à sombra se faz potência. Para esta discussão, evocaremos, portanto, o conceito derridiano de rastro num diálogo com o conceito de memória, por considerarmos que é através da memória daquelas vozes que se constroem os rastros na poesia de Conceição Evaristo.
\end{abstract}

Palavras-chave: Rastro. Memória. Poesia.

\begin{abstract}
The poetry of Conceição Evaristo is known for revealing what has long remained hidden: the female black voice, a voice that, paradoxically, always existed, but was echoed in deaf ears. Now the many lost screams of difference can be heard and the ears are put to the test, for recognizing and glimpsing the absence brought by the signs - when we first believed they brought the presence - is no easy task. Thus, we understand and propose to analyze the poems of the author: his poetry promotes the trace - the absence, the other, which carries within itself a significant potential precisely while it is a shadow, because the black voices are on the scene, but still, are not under the light, however to be in the shade becomes potency. For this discussion, we will therefore evoke the Derrida concept of trace in a dialogue with the concept of memory, because we believe that it is through the memory of those voices that the traces are constructed in the poetry of Conceição Evaristo.
\end{abstract}

Keywords: Trace. Memory. Poetry. 


\section{Introdução}

Em entrevista", Conceição Evaristo declara: "há povos que conseguem falar pelos orifícios da máscara. E falam com tanta veemência que são capazes de estilhaçar a máscara”. Podemos, facilmente, atrelar a tal declaração um caráter autobiográfico, visto que a história de Conceição se entrelaça à desses povos, tendo conseguindo alcançar um espaço, ainda reduzido para as mulheres negras, de onde emanam os vários estilhaços de quando se rompem máscaras e barreiras.

A escritora declara também que sua escrita se abre às leitoras num espaço onde elas possam se sentir em casa, reconhecidas de fato, em contraponto à lacuna existente na "literatura que nós conhecemos, essa literatura canônica, ela não nos representa e quando nos representa é sempre de uma maneira limitada, de uma maneira estereotipada" (EVARISTO, 2017, p. 01).

Propomos, aqui, que, nos poemas da escritora, a eu lírica persegue o entrelaçar de ausência e presença da mulher negra. A escrita insinua um caráter de conhecimento e autorreconhecimento identitário, mas a parcela histórica conferida a todo ato poético engajado traz à luz a ausência daquelas mulheres, cujo rastro (de lágrimas, de luta, de recordações) não se permite chegar ao objeto criador. A força dessas mulheres está exatamente em seu caráter de rastro que não se deixa apreender, na ausência que tem sido potência graças a uma memória, memória que se tenta recuperar por meio da poesia.

Queremos pensar como tal embate ocorre dentro da própria língua, especificamente na escrita de Conceição Evaristo, de maneira a oferecer uma análise de como são articulados os elementos que mantêm a instância do rastro. Averiguamos que o rastro pode ser visto como a lógica da diferença e abertura ao outro, pois reitera aquilo que é o próprio resto, potencializado justamente por seu caráter negativo, daquilo que é deixado para trás - um conjunto de memórias jogadas (dentro)fora.

\section{O dentro e o fora: a identidade negra}

Segundo Homi Bhabha (1998, p. 321), a escrita "encena o direito de significar dos escravos, não simplesmente por negar ao imperialista o 'direito de tudo a ser um nome', mas por questionar a subjetividade masculinista, autoritária, produzida no processo colonizador". Desde aí, podemos antever a escrita como um processo em que se busca um lugar de reencontro com o outro e com a nossa própria história, pois escrever, como foi dito pelo autor, emana o direito de significar, mas também suscita uma trama de embates.

O próprio processo de escrita se constrói através de uma teia de inclusão e exclusão de signos; é como se ela própria sustentasse o direito de nomear de que fala Bhabha. Quem pode nomear carrega o poder da escrita, daquele que pode ser e fazer ser; quem é nomeado fica obscurecido sob nomeações por vezes avulsas, que não integram e que não corroboram as suas memórias.

\footnotetext{
${ }^{1}$ Entrevista concedida ao projeto "Mulheres que escrevem". Disponível em: https://medium.com/mulheres-queescrevem/mulheres-que-escrevem-entrevista-conceicao-evaristo-fa243ff84284. Acesso: 14/03/2019.
} 
Escrever-se imprime um ato de emancipação própria do sujeito e também um ato de deixar-se livre da própria escrita, deixar-se livre da palavra e do nome: deixar-se livre do ser e ser, de fato, livre. Por isso que o rastro configura a exterioridade de tudo, um vir a ser. Conforme Jacques Derrida (2009, p. 91), "escrever é retirar-se. Não para a sua tenda para escrever, mas da sua própria escritura. Cair longe da linguagem, emancipá-la ou desampará-la, deixá-la caminhar sozinha e desmunida. Abandonar a palavra".

Derrida se destacou por ter formulado a lógica da desconstrução, a qual se conduz por um caminho outro às teorias metafísicas do ocidente. Com ela se questiona qualquer articulação que pretende a totalização ou a centralização das coisas. Desse modo, o filósofo traz a lume conceitos como o de rastro, em que se conjuga justamente aquilo que não está no centro das coisas.

"O rastro não é somente a desaparição da origem, ele quer dizer que a origem não desapareceu sequer, que ela jamais foi retroconstruída, a não ser por uma não-origem, o rastro, que se torna, assim, origem da origem" (DERRIDA, 1973, p. 75). O rastro nos permite ver as relações sociais por meio de um prisma linguístico (e vice-versa), pois se contrapõe, sem anular, o pressuposto da relação intrínseca significante/significado, ao apontar aquilo que fica às margens e não atende a tal lógica de significação, pois o rastro (o traço) não ganha um significado e também está desprendido de uma origem, pois ele próprio já é significante de outro significante e, assim, sucessivamente, numa cadeia eterna.

A ótica de Derrida chega a ser entendida como uma ótica engajada, visto que suscita o questionamento das limitações propagadas pelo ato da palavra, mais especificamente, pelos processos de significação entre os sujeitos. Na ideia antiga de signo, temos o significado como se fosse o objetivo final das coisas, quando, no entanto, sob um olhar derridiano, o significado limita a potencialidade das coisas, pois, achando-se o significado de tudo, morre a potência da linguagem imprimida justamente pelo momento em que se não é, em que se está num estado de vir a ser. Trazendo isso às relações humanas, significar o outro - nomeá-lo - conduz um ato de delimitação do mesmo.

Traremos tal discussão para a análise de poemas de Conceição Evaristo. Começaremos por:

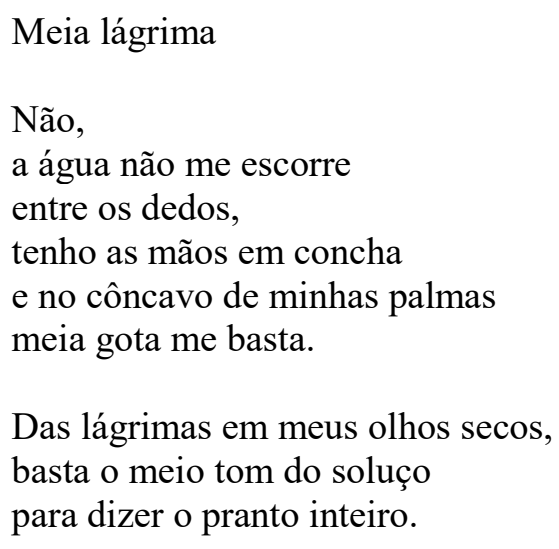

Sei ainda ver com um só olho, 


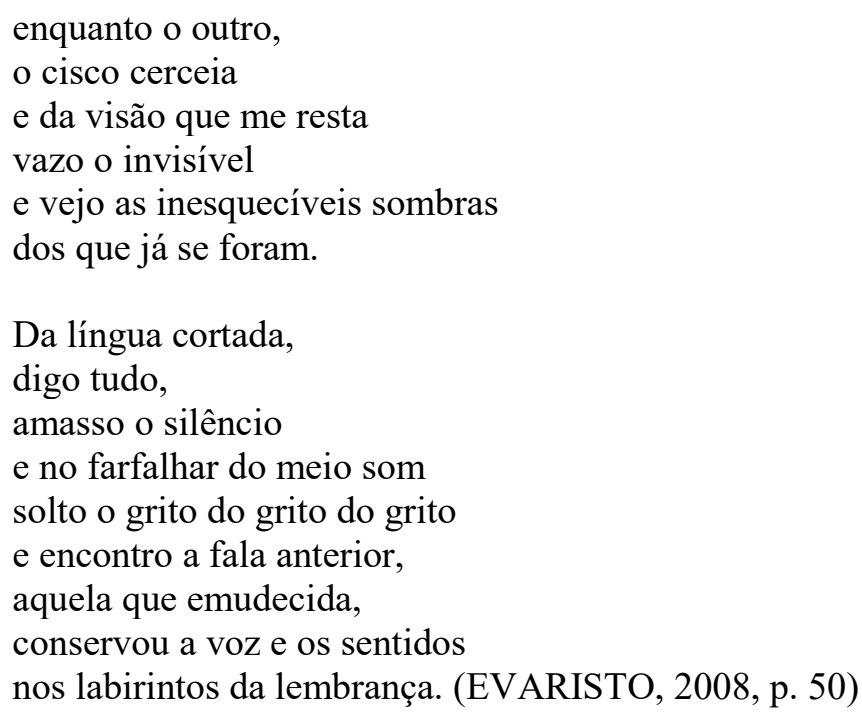

No poema em questão, notamos o trabalho com a relação de metades ("meia lágrima", "meia gota", "meio tom") que percorre um caminho metonímico inverso - da parte ao todo. Então, depois da lágrima vamos ao olho, "um só olho"; e depois do tom do soluço, vamos à língua, que também vem pela metade, "língua cortada", até chegarmos ao grito, já em seu estado de abjeto, rastro, sendo apenas "o grito do grito do grito". Podemos aplicar ao encadeamento de metades o postulado derridiano, no sentido de termos um encadeamento de significantes que permanecem em um vir a ser.

Acolhe-se, no poema, o sentido da exterioridade do signo quando dá lume àquilo que ficou de fora, a não presença. Percebemos, na última estrofe, que a eu lírica se enuncia por meio da expressão "digo tudo", mas depois, queda sua ausência, pois o que se ouve é o próprio silêncio, por meio de um grito que já virou eco do próprio eco, mas é este eco que potencializa a "fala anterior e emudecida" e conserva a voz "nos labirintos da lembrança".

Derrida considera por metafísica da presença aquela que tinha por totalidade do logos a relação significante/significado. Para ele, "a época do logos, rebaixa a escritura, pensada como medição e queda na exterioridade do sentido" (DERRIDA, 1973, p. 15). No poema de Conceição Evaristo, observamos que o conhecimento vem a lume justamente através daquilo que demarca a ausência: o grito do grito do grito.

Ademais, os trechos "amasso o silêncio" e o "farfalhar do meio som" conduzem uma maneira bem sutil para falarmos daquilo que não pode ser significado. São menções que remetem àquilo que fica no meio caminho, entre a presença e o logos, como um espectro ${ }^{2}$, como "as inesquecíveis sombras que já se foram" trazidas no poema.

Avalia-se também o movimento semântico que se faz na terceira estrofe através daquilo que se pode olhar e daquilo que é invisível. Resta à eu lírica um olho só, pois o outro está

\footnotetext{
${ }^{2} \mathrm{O}$ espectro é alguma coisa que, precisamente, não se conhece, e não se sabe, precisamente, se ele é, se existe, se responde a um nome e se corresponde a uma essência. Não se conhece: não por ignorância, mas porque esse nãoobjeto, esse presente não-presente, esse estar-lá de alguém ausente ou que partiu já não pertence ao controle do conhecimento. Pelo menos não pertence mais àquilo que pensamos entender pelo nome de conhecimento. É uma coisa que não pode ser nomeada [...] (DERRIDA, 1994, p. 6-7).
} 
cerceado por cisco. No entanto, o olho que sobrou dá vazão ao invisível composto pelas inesquecíveis sombras dos que já se foram. Mas este olho que resta ainda vê, "sei ainda ver com um olho só", o invisível é o material sabido e de sabedoria, pois ao olho que restou, enxergar o resto, "a sombra", é o que importa. Podemos conferir a este olho a pontencialidade de ele articular muito além de imagens, pois ele articula memórias, é como se ele enxergasse para dentro.

Nessa mesma esteira, falamos da necessidade de se falar a potência da escrita feminina negra e de como nela se articulam elementos emancipatórios, seja da própria mulher que escreve, seja da própria escrita levantada como o lugar das memórias, o lugar de desprendimento do signo. Este não mais aparece como imagem da coisa, mas como realização ininteligível da potência de significação. A poesia, na escrita de Conceição Evaristo, percorre o legado de memórias deixadas pelas mulheres negras. Nesse sentido, analisamos o poema abaixo:

\section{Vozes-mulheres}

A voz de minha bisavó ecoou criança nos porões do navio. ecoou lamentos de uma infância perdida.

A voz de minha avó ecoou obediência aos brancos-donos de tudo.

A voz de minha mãe ecoou baixinho revolta no fundo das cozinhas alheias debaixo das trouxas roupagens sujas dos brancos pelo caminho empoeirado rumo à favela.

A minha voz ainda ecoa versos perplexos com rimas de sangue e fome.

A voz de minha filha recolhe todas as nossas vozes recolhe em si as vozes mudas caladas engasgadas nas gargantas.

A voz de minha filha recolhe em si a fala e o ato. O ontem - o hoje $-\mathrm{o}$ agora. 
Na voz de minha filha

se fará ouvir a ressonância

o eco da vida-liberdade (EVARISTO, 2008, p. 10-11)

No título do poema, vislumbramos o signo mulher distorcido de seu caráter presença para tornar-se o rastro, mais especificamente, a voz, que se estende a um conjunto de vozes ancestrais: "a voz de minha mãe", "a voz de minha vó", "a voz de minha bisavó".

Henri Bergson chama de memória-lembrança aquela que é construída naturalmente sem uma aplicabilidade prática e que vem à tona sem esforço. "Por ela se tornaria possível o reconhecimento inteligente, ou melhor, intelectual, de uma percepção já experimentada" (BERGSON, 1999, p. 88). No caso do poema em análise, verifica-se como a memória toma o caráter de reconhecimento das "vozes mudas" de liberdade ("vida-liberdade") presente em todas as gerações de mulheres descritas no poema.

Para Bergson, a memória, “a bem da verdade, já não nos representa nosso passado, ela o encena; e, se ela merece ainda o nome de memória, já não é porque conserve imagens antigas, mas porque prolonga seu efeito útil até o momento presente" (1999, p. 89). Já para Soares e Carbonieri (2016, p. 02), a literatura surge como um importante instrumento para esse exame [da escrita feminina negra], não porque seja a transcrição de uma realidade (o que, de fato, não é), mas porque está entremeada de discursos a respeito dessa realidade, discursos que muitas vezes são conflitantes entre si. Assim, compreendemos que o que temos no poema de Conceição Evaristo é antes o efeito das vozes veladas ao longo do percurso feminino negro, do que a experiência vivida por essas mulheres, pois sabemos que, sim, tal experiência é intransferível.

Ressoa, aqui, o entendimento de Derrida a respeito de sua relutância em abraçar a correspondência entre significante e significado, entre sensível e inteligível. Com isso, avaliamos que o que nós lemos não pode ser nunca a própria experiência lida - o sensível - mas apenas o rastro daquilo que "as vozes mudas caladas/ engasgadas na garganta" tentaram ecoar.

Notemos, também no poema em apreço, a similitude sonora (repetição vogal), utilizada para descrever a presença do homem colonizador, presente em "os brancos-donos de tudo". Além disso, observamos a ascendência espacial em que habita a mulher negra que vai dos "porões do navio", passa pelas "cozinhas alheias", até chegar à favela e, por fim, ao espaço da filha, que, aliás, não é espaço, mas sim "a fala e o ato". As delimitações dos ecos afrouxaramse, não se alimentam mais das paredes entorno, agora há liberdade.

Passemos à análise de outro poema:

\author{
Recordar é preciso \\ O mar vagueia onduloso sob os meus pensamentos \\ A memória bravia lança o leme: \\ Recordar é preciso. \\ O movimento vaivém nas águas-lembranças \\ dos meus marejados olhos transborda-me a vida, \\ salgando-me o rosto e o gosto. \\ Sou eternamente náufraga,
}


mas os fundos oceanos não me amedrontam

e nem me imobilizam.

Uma paixão profunda é a boia que me emerge.

Sei que o mistério subsiste além das águas. (EVARISTO, 2008, p. 09)

Neste poema, recuperamos o signo da lágrima do poema anteriormente analisado. Dessa vez, no entanto, o signo vem metaforizado através das "águas lembranças" que transbordam dos olhos. A recordação é um momento em que se aparta do mundo e a memória se volta às águas onde ficaram perdidas as lembranças, outrora duras lembranças, mas que agora sobrevêm para reconstrução. Por isso, a eu lírica tem a liberdade para ser "eternamente náufraga/ [pois] os fundos oceanos não [a] amedrontam e nem imobilizam".

Conforme Joël Candau (2012), a memória tem um caráter mútuo com a identidade. Para ele, "toda tentativa de se descrever a memória comum a todos os membros de um grupo a partir de suas lembranças, em um dado momento de suas vidas, é reducionista, pois ela deixa na sombra aquilo que não é compartilhado" (CANDAU, 2012, p. 34). No entanto, o que havia ficado na sombra pode sobrevir uma hora ou outra, pois fica como um patrimônio das vozes mudas de um conjunto de gerações, como acontece no poema Vozes-mulheres.

Assim, o olhar para dentro, que mencionamos durante a análise de Meia lágrima, cabe muito bem a este movimento em que as lembranças, antes não compartilhadas, vêm à tona.

Voltando o olhar a Recordar é preciso, conferimos que o oceano, no qual tantas vezes os porões negreiros transitaram, agora serve para cotejar as memórias entre passado e presente, e agora a eu lírica pode reconhecer-se, "sou”, reconstrói-se e revigora-se uma identidade.

Do fogo que em mim arde

Sim, eu trago o fogo,

o outro,

não aquele que te apraz.

Ele queima sim,

é chama voraz

que derrete o bivo de teu pincel

incendiando até às cinzas

$\mathrm{O}$ desejo-desenho que fazes de mim.

Sim, eu trago o fogo,

o outro,

aquele que me faz,

e que molda a dura pena

de minha escrita.

é este o fogo,

o meu, o que me arde

e cunha a minha face

na letra desenho

do autorretrato meu. (EVARISTO, 2008, p. 19)

Segundo Candau (2012), a memória é a identidade em ação, mas ela pode, ao contrário, ameaçar, perturbar e mesmo arruinar o sentimento de identidade tal como mostram os trabalhos 
sobre as lembranças de traumas e tragédias. Neste poema, embora o caráter das memórias não esteja diretamente evocado, temos um momento de efervescência memorialística. Corpo e imagem são evocados: o corpo remetido pelo "desejo", pelo "fogo", pelo "voraz"; e a imagem é evocada no desenho feito pelo pincel e também pela "letra desenho" do "autorretrato".

Conceição Evaristo declara:

se há uma literatura que nos inviabiliza ou nos ficciona a partir de estereótipos vários, há um outro discurso literário que pretende rasurar modos consagrados de representação da mulher negra na literatura. Assenhorando-se "da pena", objeto representativo do poder falocêntrico branco, as escritoras negras buscam inscrever no corpus literário brasileiro imagens de autorrepresentação. Criam, então, uma literatura em que o corpomulher-negra deixa de ser o corpo do "outro" como objeto a ser descrito, para se impor como sujeitomulhernegra que se descreve, a partir de uma subjetividade própria experimentada como mulher negra na sociedade brasileira. Pode-se dizer que o fazer literário das mulheres negras, para além de um sentido estético, busca semantizar um outro movimento que abriga todas as nossas lutas. Toma-se o lugar da escrita, como direito, assim como se torna o lugar da vida. (EVARISTO, 2005, p. 54).

No poema Do fogo que em mim arde, haveria uma voz inflamada que reclama a própria potência falocêntrica do pincel e da pena. Na segunda estrofe, agora é a eu lírica autora de sua imagem, que não é mais apenas o desenho da primeira estrofe, é "letra desenho", portanto, agora ela tem o poder das palavras nas mãos e pode escrever-se, fazer um autorretrato, ressignificar-se muito além de seu desenho desejo pintado por mãos alheias.

Outro ponto a ser analisado é a entrada deste poema e de Meia lágrima realizada por meio dos advérbios "sim" e "não", respectivamente. Este tipo de retórica imprime, no caso, não só o eco da informação positiva e negativa que se vai passar, mas também uma exortação ao interlocutor que podemos supor nos dois poemas como sendo o homem colonizador. Exortar alguém ao diálogo confere maior ousadia ao ato de liberdade: falamos, mas queremos quem nos ouça e quem retorne.

\section{Conclusão}

Nos poemas analisados, vimos um trabalho com a memória e com o rastro. A memória é o rastro. E pô-los em evidência exige um olhar para dentro e um olhar para fora, isto porque a própria luta emancipatória se coloca dos dois lados da arena. Conquistar um lugar na escrita não exige e não quer dizer afastar o homem branco, mas negociar a partilha do uso dos instrumentos - o pincel e a pena - e promover uma rasura sobre o signo colonizador. Afinal, colere (do latim) aparece como uma das raízes do signo e quer dizer habitar, cultivar, respeitar, guardar. Deveríamos deixar o inteligível de lado e fazer o sensível ecoar.

\section{Referências}

BERGSON, Henri. Matéria e memória: ensaio sobre a relação do corpo com o espírito. Tradução Paulo Neves. 2. ed. São Paulo: Martins Fontes, 1999. 
BHABHA, Homi. O local da Cultura. Trad. de Mvriam Ávila, Eliana Lourenço de Lima Reis e Gláucia Renate Gonçalves. Belo Horizonte: Editora UFMG, 1998.

CANDAU, Joël. Memória e identidade. Tradução de Maria Letícia Ferreira. São Paulo: Contexto, 2012.

DERRIDA, Jacques. Gramatologia. Trad. de Miriam Chnaiderman e Renato Janine Ribeiro. São Paulo: Perspectiva: USP, 1973.

DERRIDA, Jacques. Espectros de Marx: o estado da dívida, o trabalho do luto e a nova Internacional. Trad. de Anamaria Skinner. Rio de Janeiro: Relume-Dumará, 1994.

DERRIDA, Jaques. A escritura e a Diferença. 2. ed. São Paulo: Perspectiva, 2009.

EVARISTO, Conceição. Gênero e etnia: uma escre(vivência) de dupla face. In: MOREIRA, Nadilza Martins de Barros; SCHNEIDER, Liane (Orgs.). Mulheres no mundo. Etnia, marginalidade e diáspora. João Pessoa: Ideia, 2005, p. 201-212.

EVARISTO, Conceição. Poemas da recordação e outros movimentos. Belo Horizonte: Nandyala, 2008.

EVARISTO, Conceição. In: Mulheres que escrevem entrevista: Conceição Evaristo, 2017. Disponível em: https://medium.com/mulheres-que-escrevem/mulheres-que-escrevementrevista-conceicao-evaristo-fa243ff84284. Acesso em: 14/03/2019.

SOARES, Cláudia Regina; CARBONIERI, Divanize. Nervous conditions: a literatura africana escrita por mulheres e o tema da educação formal, Afluente, Bacabal, v. 1, n. 3, p. 133-156, out./dez. 2016.2 Disponível em: http://www.periodicoseletronicos.ufma.br/index.php/afluente/index. Acesso em: 14/03/2019.

Rosana Arruda de Souza (rosanaarrudasouza@hotmail.com) é doutoranda em estudos de linguagem, com concentração na área de estudos literários, pelo Programa de Pós-Graduação em Estudos de Linguagem, da Universidade Federal de Mato Grosso. Mestre em estudos de linguagem, com concentração na área de estudos literários, pelo mesmo programa e pela mesma universidade (2017). Graduada em Letras/Literatura pela Universidade Federal de Mato Grosso (2014). Atuou como professora substituta no Departamento de Letras da UFMT, no período de 2016-2018.

\section{NOTAS DE AUTORIA}

Como citar esse artigo de acordo com as normas da revista

SOUZA, Rosana Arruda de. Memória rastro em poemas de Conceição Evaristo. Anuário de Literatura, Florianópolis, v. 24, n. 1, p. 13-22, 2019.

\section{Contribuição de autoria}

Não se aplica.

\section{Financiamento}


O presente trabalho foi realizado com apoio da Coordenação de Aperfeiçoamento de Pessoal de Nível Superior - Brasil (CAPES) - Código de Financiamento 001; Universidade Federal de Mato Grosso; Fundação de Amparo à Pesquisa do Estado de Mato Grosso.

\section{Consentimento de uso de imagem}

Não se aplica.

\section{Aprovação de comitê de ética em pesquisa}

Não se aplica.

\section{Licença de uso}

Este artigo está licenciado sob a Licença Creative Commons CC-BY. Com essa licença você pode compartilhar, adaptar, criar para qualquer fim, desde que atribua a autoria da obra.

\section{Histórico}

Recebido em: 18/03/2019

Aprovado em: 20/05/2019

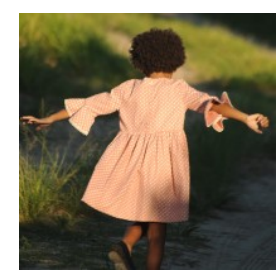

